The International

Journal of

Integrated

Engineering

\title{
Glass Transition Behavior of Poly Methyl Methacrylate Microplastics Under Various Intermediates Ratio
}

\section{Mohamad Anuar Kamaruddin ${ }^{1,2}$, Mohd Hafiidz Jaafar ${ }^{1,3}$, Mahamad Hakimi Ibrahim $^{1}$, Nastaein Qamaruz Zaman ${ }^{4, *}$, Siti Nur Hidayah Abd Rahim ${ }^{1}$}

${ }^{1}$ Environmental Technology Division, School of Industrial Technology,

Universiti Sains Malaysia, 11800 Pulau Pinang, MALAYSIA

${ }^{2}$ Center of Excellence Geopolymer and Green Technology, School of Materials Engineering,

Universiti Malaysia Perlis, 01000 Perlis, MALAYSIA

${ }^{3}$ National Poison Center,

Universiti Sains Malaysia, 11800 Pulau Pinang, MALAYSIA

${ }^{4}$ School of Civil Engineering,

Universiti Sains Malaysia, 14300 Pulau Pinang, MALAYSIA

*Corresponding Author

DOI: https://doi.org/10.30880/ijie.2019.11.01.003

Received 31 May 2018; Accepted 13 August 2018; Available online 05 May 2019

\begin{abstract}
In the recent era, a lot of plastic based intermediates have been derived and synthesized. Although the efforts area appealing, there is drawbacks which claimed that this process created another new type of pollution for waste degradation issues. Thus, many methods have been developed to find the best way for plastic waste disposal. Among others, degradation by worm under vermiculture which employs worms as decomposer agent is one of promising method. In this study, the degradation of microplastics namely Poly methyl methacrylate (PMMA) at different ratio of initiator: monomer was synthesized and further tested under vermiculture condition. The mixture was prepared through emulsion polymerization. PMMA was grinded into fine particles and sieved to the size of $500 \mu \mathrm{m}$ and then mixed with different ratio of cow manure and vermiculture setting was introduced throughout the process. Eudrilus eugeniae was used as decomposer under ambient condition. The rate of PMMA degradation was measured and characterized physically using Differential Scanning Calorimetry (DSC) to identify glass transition temperature (Tg). Thermogravimetric Analysis (TGA) was used to identify thermal degradation of the samples. Four types of PMMA samples were synthesized (PMMA 1, 2, 3 and 4). Laboratory work has demonstrated that the glass transition temperature, Tg of all pure PMMA was found to be in the range of $131^{\circ} \mathrm{C}-136^{\circ} \mathrm{C}$ respectively. The optimized sample (PMMA 4) was then further tested under vermiculture at different ratio of cow manure. The result showed that,
\end{abstract}

Keywords: DSC, microplastics, plastic waste, PMMA, TGA, vermiculture

\section{Introduction}

Microplastics is a common term in the environmental science literature referring to the milli range (1-5mm), micro range $(1-999 \mu \mathrm{m})$ and in the nano-range $(1-999 \mu \mathrm{m})$. Many plastics intermediates are widely used in short life products by which, when discarding it inappropriate way will cause accumulate of these materials and cause environmental problem due to their persistence characteristics in waste streams [1]-[3]. 
The global production demand for plastic has increased exponentially and estimated at 311 million tons in 2014 as reported by Plastic Europe. Owing to their detrimental properties including light weight, versatile, elastic and translucent material, they are well suited for a wide range of applications [2].

Discarded or unused plastic will persist for long time but can be weathered and fragmented to smaller particles. Once in the oceans, plastic undergo gradual degradation into small fragments via physical, chemical and biological processes [3]. Complete degradation of plastic polymers into natural elements takes longer time to be degraded entirely. In addition, the time spent on the water surface, the fragmentation rate, the potential of biofouling, time spent in the water column and ultimate fate of particles of different sizes and polymer types are all important factors to be considered for degradation process to occur.

The potential hazards of plastics can be detrimental based on their nature complex. Physical stress can originate from macro and microplastics by entanglement or intake, the latter causing suffocation, gastrointestinal obstruction, or even starvation [4]. Host organism may cause biological effects because plastic usually contain additive chemicals which giving the product certain properties [5]. The nature and location of sources as well as environmental conditions are influencing the occurrence in the environment.

Over the past ten years, there has been a growing concern in the scientific community about the increased accumulation of plastic fragments in the environment, their absorption of persistent organic pollutants (POPs), the human health and environmental consequences that may result [6]. Effects from ingestion of plastics have been found for zooplankton (affected photosynthesis), bivalves (affected filtering, decreased larval development), marine worms (oxidative stress), crustacean (decreased fecundity), fish (liver toxicity), and birds (decreased body condition).

Since there are a lot of plastic types that are commercially available in the market today, only a few of them are degradable and diminished easily. Poly methyl methacrylate (PMMA) is widely used with various applications in daily life. It is made of acrylic and offer high transparency that makes it ideal replacement for glass. Chemical formula for methyl methacrylate is $\mathrm{CH}_{2}=\mathrm{C}\left(\mathrm{CH}_{3}\right) \mathrm{COOCH}_{3}$ which is organic compound. This chemical is in liquid form and colourless, the methyl ester of methacrylic acid (MAA) is a monomer produced on a huge scale for the production of PMMA.

Vermiculture utilizes a few types of decomposer worms to decompose wide ranges of waste types. However, as far as the authors are concern, even PMMA is originated from organic compound, none study has reported thermoanalytical and thermogravimetric characteristics of it under vermiculture setting. Besides, there is no documented reports or literature have discussed the degradation of microplastics sunder vermiculture condition by using Eudrilus eugeniae sp. as degrader. Therefore, this work aims to determine the changes of the PMMA microplastics under vermiculture conditions with emphasize more on the glass transition of Differential Scanning Calorimetry (DSC) and Thermogravimetric Analysis (TGA)

\section{Materials and Methods}

\subsection{PMMA Preparation and Polymerization}

The preparation and polymerization of MMA was done based on the method proposed by Zhu et al. [7] without any modification. MMA powder was placed in the distilling flask with condensation distillation column and thermometer, purified under vacuum and $40^{\circ} \mathrm{C}$ in water bath. Then the purified MMA was collected from " 3 PIG" collector and poured into the conical flask $(100 \mathrm{ml})$ cover with lid. The sample was stored in the freezer at low temperature $\left(4^{\circ} \mathrm{C}\right)$ prior to use. The poly methyl methacrylate (PMMA) particles were form through emulsion polymerization of MMA. Four different ratio of initiator, potassium peroxodisulphate $\left(\mathrm{K}_{2} \mathrm{~S}_{2} \mathrm{O}_{8}\right)$ were used in emulsion polymerization process. The operating of water bath (WNB 10, Memmert, $\mathrm{GmbH}$ ) temperature was fixed at $60^{\circ} \mathrm{C}$, and deionised water $(18.2$ million $\mathrm{ohm}-\mathrm{cm})$ was poured in the emulsion reactor and stirred until it reached equilibrium temperature approximately after $12 \mathrm{hrs}$ of mixing.

Buffer and surfactant were poured into the reactor, after a few minutes the monomer was carefully poured into the mixture solution and retain for a period of time to achieve equilibrium temperature. Finally, the initiator was added approximately within 1 minutes to make sure it mixed well with the mixture solution by using mechanical stirring at $200 \pm 1 \mathrm{rpm}$ until homogeneous condition reached. The polymerization process was carried out up to 1 hour 15 minutes. Once complete, the vial was removed from the hood and the sample was poured in the mold and only detached for further laboratory work. Table 1 simplified the samples conditions and their composition in part per hundred (phr).

\subsection{Preparation of PMMA and Substrate}

PMMA was ground into fine particles and sieved with $500 \mu \mathrm{m}$ aperture size. The PMMA and substrate composition (cow manure) as decomposer was prepared and placed in 5 different containers with labelled. $10 \mathrm{~g}$ of vermicast for each container to give more space for Eudrilus eugeniae sp to consume the fine particles of PMMA. 
Table 1 - PMMA sample mixtures

\begin{tabular}{|c|c|c|c|c|}
\hline Variables & PMMA 1 & PMMA 2 & PMMA 3 & PMMA 4 \\
\hline pH DI water & \multicolumn{4}{|c|}{9.8} \\
\hline $\begin{array}{l}\text { Methyl } \\
\text { methacrylate }\end{array}$ & \multicolumn{4}{|c|}{100} \\
\hline Potassium Peroxodisulphate $\left(\mathrm{K}_{2} \mathrm{~S}_{2} \mathrm{O}_{8}\right)$ & 1 & 2 & 3 & 4 \\
\hline $\begin{array}{l}\text { Sodium } \\
\text { Bicarbonate }\left(\mathrm{NaHCO}_{3}\right)\end{array}$ & \multicolumn{4}{|c|}{0.11} \\
\hline $\begin{array}{l}\text { Sodium Dodecyl } \\
\text { Sulfate }\left(\mathrm{C}_{12} \mathrm{H}_{25} \mathrm{NaSO}_{4}\right)\end{array}$ & \multicolumn{4}{|c|}{1.26} \\
\hline Mixing Temperature & \multicolumn{4}{|c|}{$60^{\circ} \mathrm{C}$} \\
\hline Mixing speed & \multicolumn{4}{|c|}{$200 \pm 1 \mathrm{rpm}$} \\
\hline Mixing time & \multicolumn{4}{|c|}{1 hour 15 minutes } \\
\hline
\end{tabular}

Table 2 - PMMA and substrate

\begin{tabular}{lcc}
\hline Sample label & Ratio & $\begin{array}{c}\text { Glass } \\
\text { temperature, } \mathbf{T g}\left({ }^{\circ} \mathbf{C}\right)\end{array}$ \\
\hline Pure Cow manure & $100: 0$ & 53.03 \\
Mixture 10\% PMMA4 of Cow manure & $90: 10$ & 56.50 \\
Mixture 20\% PMMA4 of Cow manure & $80: 20$ & 50.60 \\
Mixture 30\% PMMA4 of Cow manure & $70: 30$ & 46.73 \\
Mixture 40\% PMMA4 of Cow manure & $60: 40$ & 43.61 \\
\hline
\end{tabular}

Table 2 lists down different compositions of PMMA with respect to cow manure composition. In this work, PMMA4 was chosen as the main sample to be mixed homogenously with cow manure because the plastic sample crushed and disintegrated much easier during crushing test (data not shown). The finely grinded cow manure and PMMA (passing sieve aperture $500 \mu \mathrm{m}$ ) were then mixed accordingly in dry mass.

\subsection{Differential Scanning Calorimetry (DSC)}

Thermal analysis was performed on the prepared sample to evaluate their glass transition temperature (Tg) by using DSC 6 (Perkin Elmer, USA). Sample with a mass of approximately 5-10 mg were heated from $0{ }^{\circ} \mathrm{C}$ to $150{ }^{\circ} \mathrm{C}$ at a rate of $10^{\circ} \mathrm{C} / \mathrm{min}$. The temperature was maintained for $1 \mathrm{~min}$ before subsequently cooled to $0{ }^{\circ} \mathrm{C}$ at $10^{\circ} \mathrm{C} / \mathrm{min}$. The aim was to remove any processing history. The same steps were repeated for the second scan and others sample. PMMA 1 and 2 have two tests, while PMMA 3 and PMMA 4 have 4 tests for each of the sample.

For the case of decomposition of PMMA under vermiculture setting, vermicast produced from Eudrilus eugeniae sp decomposition activity which digested polymeric substances was subject to DSC test similar to the method used for PMMA samples.

\subsection{Thermogravimetry Analysis (TGA)}

The PMMA samples were dried at room temperature, approximately two to three days. TGA experiment were performed by using Mettler-Toledo TGA/DSC 1. Powdered samples of the virgin PMMA having masses ranging from 5 to $10 \mathrm{mg}$, each sample was placed in an open aluminum oxide crucible without lid with maximum $1000{ }^{\circ} \mathrm{C}$ maximum heated, were heated from room temperatures $30^{\circ} \mathrm{C}$ to $800{ }^{\circ} \mathrm{C}$, at heating rates of $20^{\circ} \mathrm{C} / \mathrm{min}, \mathrm{N}_{2}$. The experiments were conducted in flowing a nitrogen atmosphere with $50.0 \mathrm{ml} / \mathrm{min}$. The gas supply line was equipped with a valve that allowed for quick switch of gasses while an experiment was being performed.

Both instruments were computer controlled, allowing recording of experimental data for further treatment. The thermogravimetric weight loss curve (TG,mg) and weight loss derivative curve (DTG, $\mathrm{mg} / \mathrm{min}$ ) were recorded as a function of time and temperature. From the difference between the sample experiment and the base-line was calculated for the actual weight of the sample. 


\section{Reults and Discussion}

\subsection{PMMA Forming Ability}

Fig 1(a) - (d) illustrates the PMMA forming ability once have been dried. Generally, all the PMMA matrix were prepared under different initiator and monomer as shown in Table 1.

PMMA 1 was formed within 24 minutes after the mixing while PMMA 2 took about 18 minutes, then 12 minutes for PMMA 3 and 6-7 minutes for PMMA 4. In this case, it was observed that the molten mixture of PMMA 1 and 2 were homogenously mixed without any texture or impurities been formed. For PMMA 3, there was aggregates or lump was formed as a result from different initiator and monomer ratio.

Meanwhile, PMMA 4 mixture was observed to exhibit higher viscosity. This was evident as when the molten matrix was started to harden, there was aggregation of the initiator. In this work, the nitrogen gas was not used for purging. Nitrogen gas is necessary for many polymerizations simply because moisture may affect the initiator or catalyst that is used. Oxygen, itself, may also interfere and act as retarder for an undesired pathway including polymerization [8]. Even polymerization takes place, it will occur just at relatively lower rate, thereby oxygen reacts and forming peroxy radicals which can initiate polymerization.
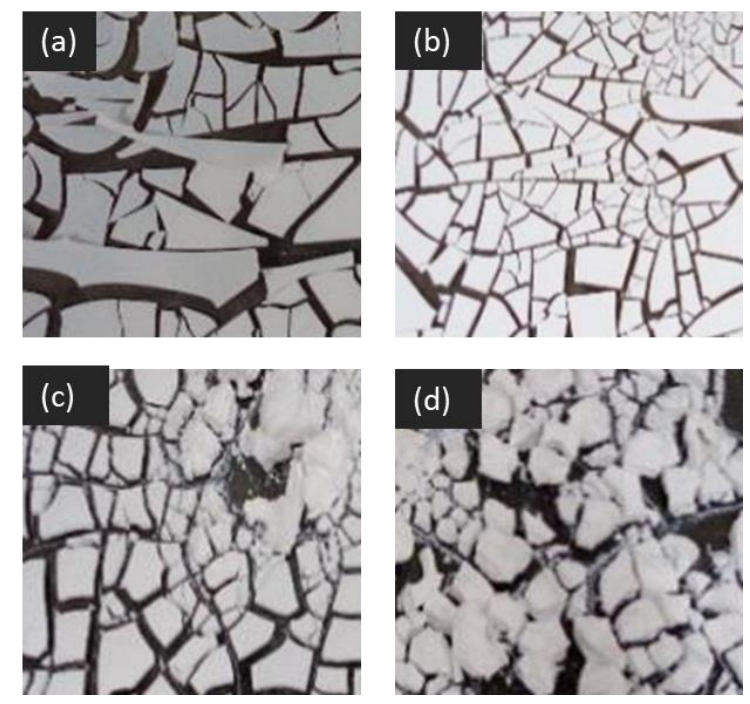

Fig 1 - (a) PMMA1, (b) PMMA2, (c) PMMA 3 and (d) PMMA 4

\subsection{Glass Transition Temperature for PMMA}

Generally, glass transition temperature $(\mathrm{Tg})$ influences the mechanical and physical characteristics of polymeric materials for wide range applications [9]. The DSC curve for PMMA 1 is shown in Fig. 2. In general, at temperature of $0^{\circ} \mathrm{C}$ indicated a weak transition showing existence of water in the sample or the purge gas. Despite exhibiting transition temperature of endotherms, they may appear different from a melting peak. The transition usually appears due to condensation of water on both reference and sample pans. In addition, the peaks may appear slightly below $0{ }^{\circ} \mathrm{C}$ because of the dissolution of impurities by the moisture from the sample and pans [10]. Reproducible results may not be possible due to the presence of water in the sample because it would lower the transition temperatures and changed to plasticizer. During the experiment, volatilization of water causes an endothermic peak and baseline shift [11]. A perturbation in the baseline caused by the presence of water in the purge gas poses challenge for detection of real transition around $0{ }^{\circ} \mathrm{C}$.

The glass transition temperature Tg is physical characteristic of plastics which is important. Polystyrene, PMMA and polybutadiene are amorphous polymers, which known to be hard and brittle at temperatures below Tg. They became elastic like rubber or liquefy when heating to temperatures above $\mathrm{Tg}$ depending on their molecular weight and/or degree of cross-linking [12]. As shown in Fig. 2, the DSC curve of the samples, revealed a slight endothermic region occurring at $\mathrm{Tg}=132.04{ }^{\circ} \mathrm{C}$. It could be interpreted that this phenomenon is related to the evaporation of unreacted monomer at temperature above the $\mathrm{Tg}$ of the MMA monomer. A similar observation was reported in the studies of the $\mathrm{Tg}$ of acrylic resin used in dentistry by utilising the DSC techniques [4, 9]. While for PMMA 2, PMMA 3 and PMMA 4 were observed at $132.4{ }^{\circ} \mathrm{C}, 134.08^{\circ} \mathrm{C}$ and $135.97^{\circ} \mathrm{C}$, respectively.

From the figure, it was further observed that Potassium Peroxodisulphate $\left(\mathrm{K}_{2} \mathrm{~S}_{2} \mathrm{O}_{8}\right)$ which used as the initiator produced the highest glass transition when their ratio was at the most at constant monomer. This result shows that the molar mass of the PMMA react as cross-linking points which could not resist the polymer chains that exhibit greater large polymolecularities from the initiator [13]. 


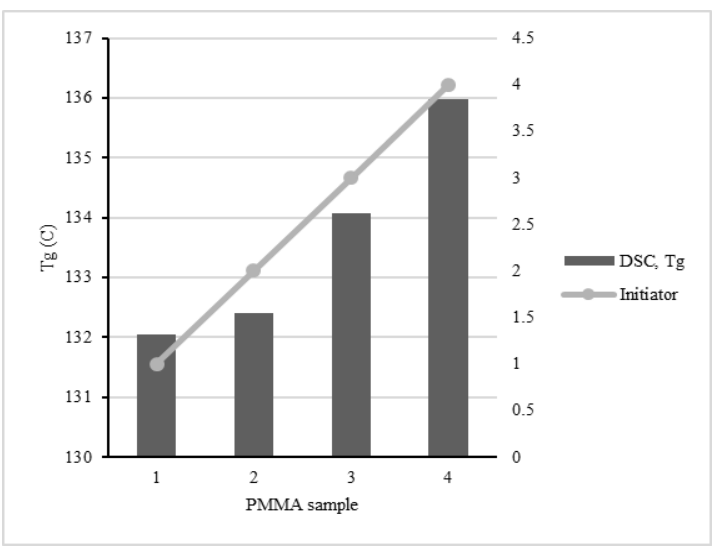

Fig 2 - Glass transition of PMMA samples with respect to different initiator

All the DSC curves analyzed, the PMMA transition temperature are in the range of 132 to $136{ }^{\circ} \mathrm{C}$, lower than commercial grades of PMMA range from 85 to $165^{\circ} \mathrm{C}$. Such a difference in the range was due to the vast number of commercial [14] compositions presence with the co-monomers other than methyl methacrylate.

\subsection{Glass Temperature of Cast (Mix Between Cow Manure and PMMA 4 Based on Ratio)}

The glass transition temperature for the mixture between PMMA and cow manure was analyzed for DSC under different ratio. Figs $3-7$ show the glass transition temperature under various conditions. From Fig. 3 , the Tg value was $53.03{ }^{\circ} \mathrm{C}$. While Cast 2 in Fig. 4 at $\mathrm{Tg}=56.50{ }^{\circ} \mathrm{C}$. Then Fig. 5 showed Cast 3 at $\mathrm{Tg}=50.60{ }^{\circ} \mathrm{C}$. Next, the illustrated in Fig. 6 showed Cast 4 at $\mathrm{Tg}=46.73{ }^{\circ} \mathrm{C}$. Finally, Cast 5 as shown in Fig.7, indicated that the $\mathrm{Tg}$ value was observed at $43.61{ }^{\circ} \mathrm{C}$. These finding assumed that the presence of vermiculture condition and cow manure caused the earthworms population to be abundant whereby the microbes presence from the surrounding habitat.

These microorganisms multiply in number with the passage food. The conducive environment in the gut due to the secretion of mucus creates a conducive environment for the multiplication of the microbes. This condition facilitates the breakdown microplastics tested otherwise seemingly difficult to breakdown polymers

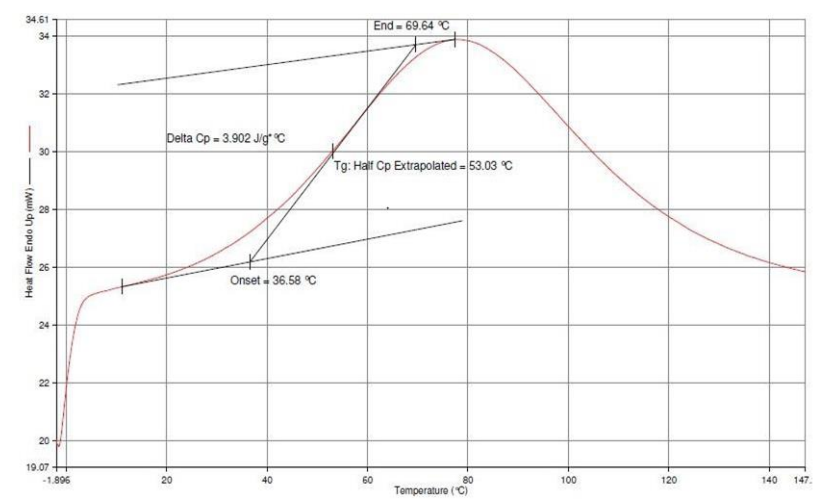

Fig. 3 - The DSC curve of Cast 1

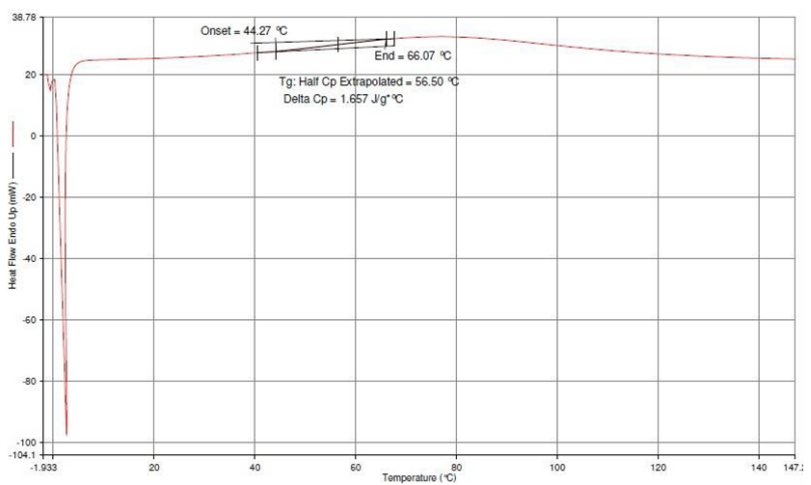

Fig. 4 - The DSC curve of Cast 2 


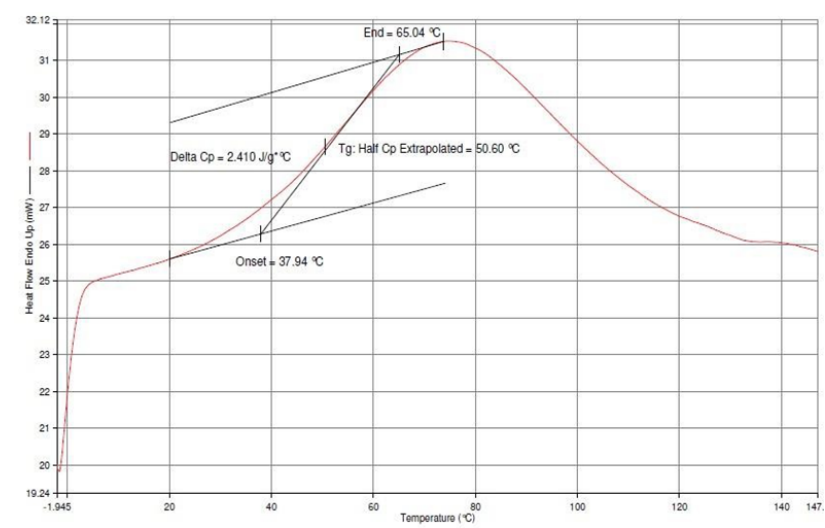

Fig. 5 - The DSC curve of Cast 3

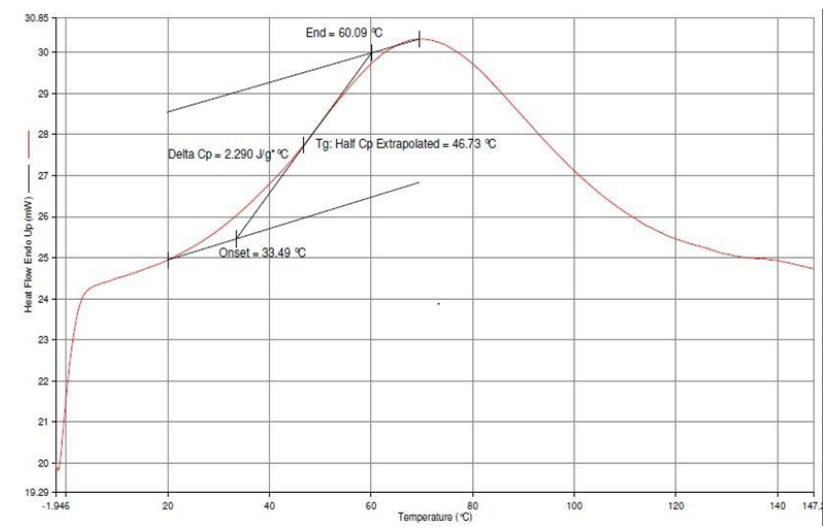

Fig. 6 - The DSC curve of Cast 4

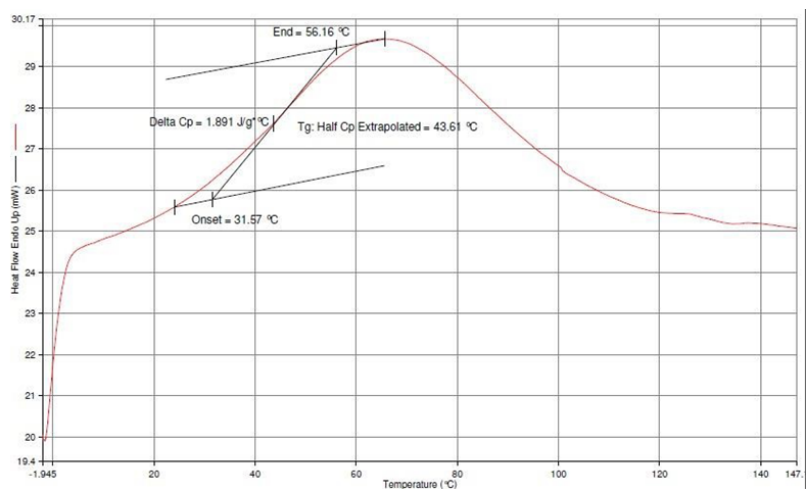

Fig. 7 - The DSC curve of Cast 5

\subsection{Thermogravimetry Analysis (TGA)}

TG curves of 4 samples of PMMA (1, 2, 3 and 4) is shown in Fig 8. In order for appropriate thermal treatment temperature selection, the weight loss of PMMA 1 as a function of temperature was measured. The curves shows that when the PMMA 1 was heated up to $165.95^{\circ} \mathrm{C}$, the weight loss started to occur. As the rise of temperature in the DSC curves, the weight of PMMA 1 kept reducing and it decreases sharply when the temperature was within $355.53{ }^{\circ} \mathrm{C}$. When the temperature was higher than $440^{\circ} \mathrm{C}$, the sample was degraded and produced $0.81 \%$ residue. It was attributed to the PMMA 1 has lost most of functional groups during the low - temperature heating process. This indicates that the instable functional groups would be pyrolyzed mostly at low temperature.

Meanwhile, for the case of PMMA 2, the weight loss was maximum when the temperature was $165.05{ }^{\circ} \mathrm{C}$ and it further continue to record weight loss when the temperature at $356.57{ }^{\circ} \mathrm{C}$ until. At this temperature, only $1.26 \%$ the residue was left.

PMMA 3 data for weight loss against temperature indicated that when the sample was heated up to $159.14{ }^{\circ} \mathrm{C}$ the weight loss started to occur. The sharp reduction of weight at the $357.26^{\circ} \mathrm{C}$ whereby only $0.46 \%$ of weight from initial condition has left. For the case of PMMA 4, when the sample was heated and the sample lost its weight at $158.99{ }^{\circ} \mathrm{C}$, 
become more significant when the temperature reached $355.80{ }^{\circ} \mathrm{C}$. Only $1.19 \%$ of weight left. Fig 9 simplifies the temperature changes for all PMMA during TGA protocol.

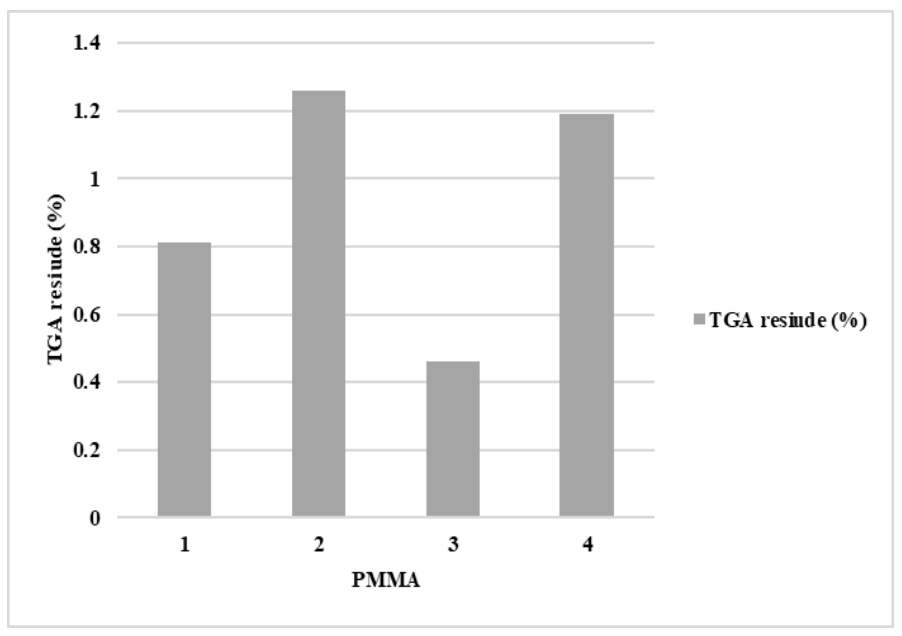

Fig. 8 - TGA resiudes against PMMA

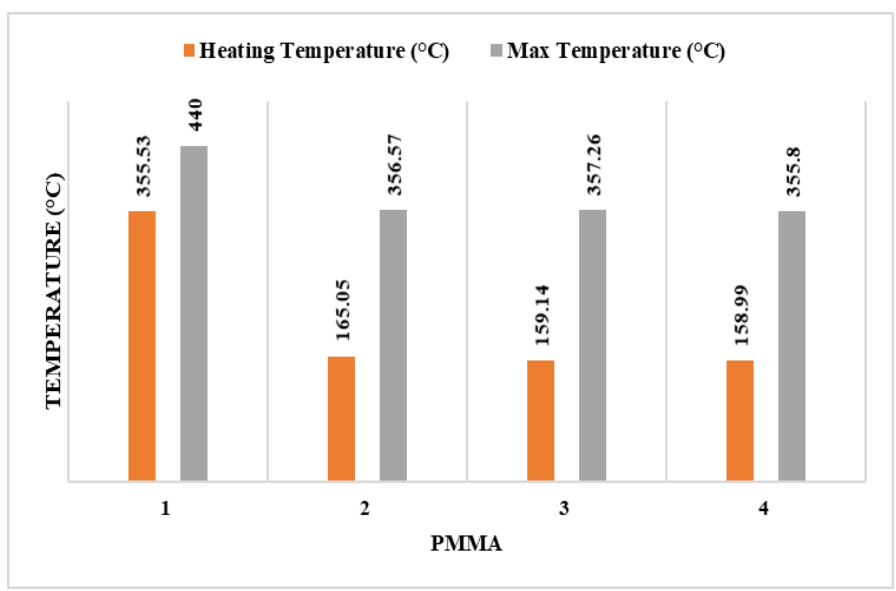

Fig. 9 - TGA for PMMA samples

\section{Conclusions}

The PMMA mircroplastics behavior under DSC and TGA protocol. The following is the summary of the work:

- PMMA samples exerted endothermic behavior at different melting peak glass transition. From the work, the maximum glass transition, Tg for all the samples were in the range of 132 to $135{ }^{\circ} \mathrm{C}$.

- Marginal increase of temperature with respect to initiator ratio from 1 to 4 indicating that polymerization of PMMA did not only dependent on the temperature itself. Rather, others controlling factors are needed to evaluate the particle morphology

- The thermal degradation of PMMA produce primary and tertiary radical. The PMMA samples for all cow manure composition showed relatively lower glass transition temperature, $\mathrm{Tg}$ in the range of 43 to $56{ }^{\circ} \mathrm{C}$ proven that microplastics degraded.

\section{References}

[1] Piña, X., García-Rivera, M. A., Espinosa-Valdemar, R. M., Vázquez-Morillas, A., Beltrán-Villavicencio, M. and De La Luz Cisneros-Ramos, A. (2017). Biodegradation of compostable and oxodegradable plastic films by backyard composting and bioaugmentation. Environmental Science and Pollution Research, 24, 25725-25730.

[2] Kamaruddin, M., Abdullah, M., Zawawi, M. and Zainol, M. (2017a) Potential use of plastic waste as construction materials: recent progress and future prospect. IOP Conference Series: Materials Science and Engineering, IOP Publishing, 012011. 
[3] Kamaruddin, M. A., Yusoff, M. S., Rui, L. M., Isa, A. M., Zawawi, M. H. and Alrozi, R. (2017). An overview of municipal solid waste management and landfill leachate treatment: Malaysia and Asian perspectives. Environmental Science and Pollution Research, 24(35), 1-33.

[4] Kamaruddin, M. A., Yusoff, M. S., Ibrahim, N. and Zawawi, M. H. (2017b) Resource recovery from municipal solid waste by mechanical heat treatment: An opportunity. AIP Conference Proceedings, 020031.

[5] Andrady, A. L. (2011). Microplastics in the marine environment. Marine Pollution Bulletin, 62, 1596-1605.

[6] Lusher, A. (2015). Microplastics in the marine environment: Distribution, interactions and effects. Marine Anthropogenic Litter. Cham: Springer, pp 245-307.

[7] Zhu, X., Chen, J., Zhou, N., Cheng, Z. and Lu, J. (2003). Emulsion polymerization of methyl methacrylate under pulsed microwave irradiation. European Polymer Journal, 39, 1187-1193.

[8] Sargsyan, A., Tonoyan, A., Davtyan, S. and Schick, C. 2007. The amount of immobilized polymer in PMMA SiO2 nanocomposites determined from calorimetric data. European Polymer Journal, 43, 3113-3127.

[9] Elshereksi, N. W., Mohamed, S. H., Arifin, A. and Ishak, Z. A. M. 2014. Thermal characterisation of poly (methyl methacrylate) filled with barium titanate as denture base material. Journal of Physical Science, 25, 15-27.

[10] Kaniappan, K. and Latha, S. 2011. Certain investigations on the formulation and characterization of polystyrene/poly (methyl methacrylate) blends. International Journal of ChemTech Research, 3, 708-717.

[11] Sarı, A., Alkan, C. and Karaipekli, A. (2010). Preparation, characterization and thermal properties of PMMA/nheptadecane microcapsules as novel solid-liquid microPCM for thermal energy storage. Applied Energy, 87, 15291534.

[12] Rieger, J. (2001). The glass transition temperature Tg of polymers-comparison of the values from differential thermal analysis (DTA, DSC) and dynamic mechanical measurements (torsion pendulum). Polymer Testing, 20, 199-204.

[13] Buathong, S., Peruch, F., Isel, F. and Lutz, P. (2004). From free radical to atom transfer radical polymerization of poly (ethylene oxide) macromonomers in nanostructured media. Designed Monomers and Polymers, 7, 583-601.

[14]Lee, D. C. and Jang, L. W. (1996). Preparation and characterization of PMMA-clay hybrid composite by emulsion polymerization. Journal of Applied Polymer Science, 61, 1117-1122. 